\section{Counterpart to 'Frontiers'}

\section{Tokyo}

JAPAN'S Ministry of International Trade and Industry (MITI) is about to launch a sequel to the Human Frontiers science programme. But unlike Frontiers, which is aimed at basic research on the brain, the new project is aimed at the development of manufacturing technology, an area in which Japan is a world leader.

The Intelligent Manufacturing System (IMS) project is the brainchild of a committee of academics, industrialists and MITI officials headed by Hiroyuki Yoshikawa, dean of the faculty of engineering at Tokyo University. The committee, established last year, proposes the establishment of an international research centre in the United States or Europe with funding of about $\$ 1,000$ million over ten years. In the committee's proposal, which was explained to government officials of the United States, Europe and Australia at a meeting on 19 January, the Japanese government and private sector will provide about 60 per cent. of the funds and other countries the rest.

The institute will develop fully automated manufacturing systems, including product design, intelligent robots for product manufacture and automated systems for retailing and distribution. An important element will be to develop standardized systems that can be interlinked and used anywhere in the world.

Research at the proposed institute will be divided into about 100 projects over the ten-year period, each with budgets of about $¥ 1,000-Y 1,500$ million (\$7-\$10 million). MITI has won the unusually large sum of $¥ 110$ million $(\$ 700,000)$ in preparatory funds for the project in the budget allocations for fiscal year 1990 set by the Ministry of Finance at the end of last year.

Yuji Furukawa of the department of mechanical engineering at Tokyo Metropolitan University, one of the project organizers, says that about a hundred 'core member' companies will donate $\mathbf{Y} 12$ million $(\$ 85,000)$ each to finance the conceptual design of IMS. Already 50 companies, including Toshiba, FANUC (one of the world's leading manufacturers of machine tools and robots), Kawasaki Heavy Industries and "several big US companies", have formally or informally agreed to join, according to Kunihiko Umehara of the Industrial Machinery Division of MITI. And last week the Michigan-based Society of Manufacturing Engineers agreed in discussions with Furukawa to act as a 'window' for the project in the United States.

Organizers of the project are asking for project proposals from companies, universities and research organizations in
Japan and overseas to be submitted by 30 June at the latest. If all goes according to plan, an international committee of academics drawn from the United States, Europe, Japan and possibly other countries will assess the proposals and draw up firmer plans for the project at a meeting on 3 and 4 June in time for MITI to submit a budget request for fiscal 1991 in late August.

The project is in many ways reminiscent of Frontiers but has important differences. IMS, like Frontiers, is being promoted as a way of 'paying back Japan's debt to the Western world' at a time of massive trade deficits with the West. And when first proposed by MITI, Frontiers, like IMS, was put forward as a means of developing intelligent robots. But this goal was quietly dropped by the academics from Japan and Western nations who moulded Frontiers into its final form. For IMS, it is academics who are proposing robot development.

Umehara says the IMS research institute will probably be set up in the form of a foundation, like Frontiers. But, unlike Frontiers, which took four years of protracted discussions to launch and shrank from an initial proposal of $\$ 350$ million a year to $\$ 20$ million, Umehara expects IMS to get under way next year with a level of funding close to that proposed.

A foreign government official who

\section{PEST CONTROL}

\section{Sydney}

Australian scientists are to test a new method of controlling the blowfly (Lucilia cuprina), an agricultural pest of sheep which costs farmers $A \$ 200$ million a year, through the release of blowflies that have been genetically manipulated in a unique way.

Scientists at the Commonwealth Scientific and Industrial Research Organisation (CSIRO) will release 700 million blowflies during the summers of 1990 and 1991 on the remote Furneaux group of islands north of Tasmania. Each male fly will deliver a double genetic blow. A sex-linked translocation will cause a high frequency of sterility in the male line while several other genetic mutations will bring about blindness in the female line.

According to Rod Mahon, senior research scientist within the Division of Entomology at the CSIRO, the Furneaux experiment is the first use of genetic manipulation to suppress an insect population. "Ongoing suppression is achieved as a result of the blindness mutation and sterility", he says, "the sons and daughters attended the briefing on 19 January says that MITI has obviously learned a lot from Frontiers. This time, pamphlets describing the project in English are clear and lucid. MITI has avoided involvement of other ministries and agencies which delayed the launch of Frontiers.

Yoshikawa and Furukawa have done considerable groundwork, visiting government officials, universities and research institutes in the United States and Europe to explain the project and win support before its announcement. And the topics for research are in areas where Japan has considerable expertise, making IMS less likely to be interpreted as an attempt to pick the brains of Western scientists.

Nevertheless, the London Financial Times newspaper has suggested that the project's aim to standardize manufacturing technology might make it easier to duplicate Japanese factories outside Japan and that Japan is lagging in the development of computer software for use on the shop floor. But Furukawa says that IMS has nothing to do with the movement of Japanese factories overseas. The aim of IMS is to transfer Japanese expertise in manufacturing to the West and to develop new fully automated and standardized technologies for the "benefit of all mankind". And Umehara says that foreign government officials, academics and members of industry have given a generally "warm response" to IMS in contrast to the "chilly reception" that first greeted Frontiers.

David Swinbanks

\title{
Double blow for blowflies in Australia
}

continue to carry this mutation unlike other suppression systems in which only sterile males are released." In the ongoing screw-worm eradication programme in Texas and Florida the continuing release of infertile males is necessary. "If a release is missed, suppression is lost", says Mahon.

In a small trial using the genetically manipulated blowflies, mutations were still present in the population nine months after the release of males had ended. The blowflies are released from the air so a reasonably high density of sheep per hectare is needed to make the system cost-effective. "We feel it is possible to totally eradicate the sheep blowfly from the island state of Tasmania but on the mainland a strategy of continuing suppression, in selected high risk areas, may be more cost effective than attempting eradication", says Mahon.

The Lucilia blowfly was introduced to Australia, probably from South Africa or India. It is, according to Mahon, extremely well adapted to living on live sheep and can rapidly develop resistance to insecticide as it undergoes 6-10 generations a year.

Tania Ewing 